\title{
The power of individuals and the dependency of nations in global eradication and immunisation campaigns
}

\section{William Muraskin}

At one time historians emphasised the 'Great Man in History' concept. That idea was later pushed aside by the realisation that larger, more important forces were at work. The individual's importance shrank as the role of massively expanded governments, multi-national corporations, and institutional science took centre-stage as the movers and shakers of world events. Without denying the importance of such forces and institutions, I have made it my concern to study the continued centrality and indispensability of individuals in making things happen in international public health. I have spent the better part of the last quarter-century looking at how the right men - and they tended to be men, American men in particular - in the right place, at the right time have created the conditions to radically accelerate development and delivery of vaccines for the children of the developing countries.

I have focused intensively on the International Task Force on Hepatitis B Immunisation ${ }^{1}$ - led by James Maynard, Alfred Prince and Richard Mahoney; the Children's Vaccine Initiative ${ }^{2}$ led by or influenced by Scott Halstead, Philip Russell and Roy Widdus; the Bill and Melinda Gates' Children's Vaccine Programme ${ }^{3}$ led by Mark Kane and James Maynard; the Global Alliance for Vaccines and Immunization ${ }^{4}$ created by Mark Kane, Tore Godal, Jacques-Francois Martin, Steve Landry and Amy Bateson; the Rockefeller Foundation's Public-Private Partnership project ${ }^{5}$ single-handedly championed by Ariel PablosMendez (with the support of Timothy Evans) - many of which were ultimately adopted by the Gates Foundation and (incorrectly) seen as 
originating with it; and the global polio eradication campaign ${ }^{6}$ conceived by William Foege, Alan Hinman, Ciro de Quadros and run by Bruce Alyward. Driven by a powerful moral imperative and social consciousness, these dozen and a half men fought to make things happen that under normal circumstances would not have happened in the fight to save the lives of countless children using vaccines and immunisation as their tools.

Among their supporters have been many engaged and committed vaccine champions within the scientific community: scientist/activists working for what they believed was clearly the 'Greater Good'. William (Bill) Foege (former head of the American CDC and the Task force for Child Survival, adviser to the Rockefeller and the Gates Foundations) has talked of the importance of a 'Network of Scientists' as the people who should be the prime movers of global initiatives - even if being such would mean marginalising (or even undermining) the influence of the World Health Organization (WHO).

The host of global goods that have been achieved by these few men using vaccines and immunisation as their tools is truly staggering. I started out as a researcher enthralled by the moral fervour of the people I was studying and their dedication to achieving their ends despite the apparently overwhelming human, monetary and physical obstacles. Nothing would stop them from carrying out what they saw as the morally right thing, and I found it very difficult not to see the world as they did: a world in which children are needlessly suffering and dying because of uncaring, often incompetent, bureaucrats and their endlessly feuding organisations. These inspired men no doubt had a can-do spirit that contrasted markedly with the prevailing ethic in international public health. ${ }^{8}$

However, it has become increasingly clear to me that these great achievements have come at a very steep price, a price which has largely been obscured because it has been paid by people whose concerns and needs have not been widely known, or if known, have been considered unimportant among the network of scientist-activists and influential individuals who make international public health policy their domain. To repeat, there has been considerable but nearly invisible 'collateral damage' inflicted on the world by the good works of global policy makers, and this damage threatens to become worse as time passes. 


\section{The problem of power}

When global leaders decide a course of action, they exercise a potent form of policy-making power. If children's lives are being saved, if the public's health improves, it is easy to focus on leaders' achievements and miss unpleasant things that are going on simultaneously. Regardless of the benefits they bring about, however, global leaders' power comes at the expense of other real or potential sources of authority. When costbenefit analyses of vaccine campaigns and eradication programmes are prepared, the list of items to be ranked are restricted to things that can be easily quantified. Increases and decreases in power among legitimate rival stakeholders is not considered.

Since gains and losses of power are not admitted to by global policy makers, those who successfully work the levers of global health programmes often conflate their personal agendas with 'global goods', allowing them to believe that what they subjectively want is objectively sought by everyone - or at least by every right-thinking person. For example, eradication campaigns have come to be seen as the ultimate and finest example of public health in action. ${ }^{9}$

It is widely believed that to not eradicate a disease when it is feasible to do so will be seen as a blot on our collective reputation; something for which future generations will condemn us. ${ }^{10}$ Yet, whether admitted or not, global health power-brokers can, and regularly do, take advantage of this belief to subvert the priorities of developing world governments, national medical professional associations, local communities and millions of families. Too often, countries' autonomy and authentic independence are the collateral damage of top-down global health. Unfortunately, this happens to a greater or less degree in most global immunisation initiatives, ${ }^{11}$ but the most extreme and blatant loss of autonomy comes with eradication campaigns. Such campaigns literally hijack the public health agendas of the world without the sponsors even taking notice of it - blinded as they are by their deeply held personal visions of the public good. Alarmingly, we can expect a dozen or more such campaigns to be waged simultaneously in the near future throughout the developing world.

As I wrote in my book Polio Eradication and Its Discontents, ${ }^{12}$ the global polio campaign is an egregious example of the often underhanded process (means) that has generally been employed to save the 
lives of children (ends). There was and still is a downside when a few inspired but relentless individuals successfully push through global initiatives in which vaccines are not understood as a means to help build a long-term sustainable health system but rather as indispensable weapons for winning dramatic, but short-term, wars against particular microbes.

The reality underneath the hype

The origin of the global polio eradication campaign is as astounding as it is disheartening. It is important not just as a history lesson but as a warning of the effects of power when it is exercised without accountability by self-chosen crusaders. It is a warning that is important for the future, because an all-out war on microbes is being planned right now by eradication proponents who intend to prevail regardless of developing-country governments', or their peoples', choices.

At the conclusion of the successful smallpox eradication effort in 1977, most of the world's public health communities led by the WHO took a 'no more vertical eradication programmes' position. Instead, they turned toward a new emphasis on Primary Health Care for All by the year 2000. ${ }^{13}$ Immunisations, but not disease eradication, would be part of the new emphasis, but not pivotal to it. They would be just one component in the larger primary health care system. There were many vehement objections to this 'Health for All', especially in the United States. In particular the Rockefeller Foundation saw the WHO as dysfunctional and unable to carry out its mandate as the chief health agency in the world. The Rockefeller Foundation fired back with an 'interim' concept of 'selective primary health care' authored by Kenneth Warren and Julia Walsh which, despite its name, was aimed at undermining the new policy by emphasising immunisation systems, rather than general primary health systems, as the critical goal for policy makers. ${ }^{14}$

However, others were not as offended by the marginalisation of vaccines per se, as they were appalled by the negative attitude toward eradication. They feared that eradication as a tool of public health was on the verge of itself being 'eradicated'. This possibility was for them personally intolerable. 
In 1980 at a National Institutes of Health conference convened by De Witt Stetten Jr, deputy director of the NIH Fogarty Centre, Stetten raised the issue of what was to be done to correct the situation. ${ }^{15}$ The majority of participants expressed opposition to the WHO's new public health policy and talked of the need to find a disease - any disease - that could be effectively eradicated relatively quickly and cheaply to prove the continued relevance of eradication as a tool - perhaps 'the tool' - of international public health. Of the many possibilities raised, only three diseases were seen as feasible for eradication: measles, yaws and poliomyelitis. Measles was strongly favoured by Stetten and Alan Hinman, who was then the foremost measles eradication advocate.

Stetten and his colleagues were influential enough that other largescale expert conferences on these three diseases were convened in the next few years with the hope, and expectation, that at least one of the groups would champion an eradication campaign. It quickly became clear that measles was not eradicable given existing technology, and that yaws was not a global problem, which made the next polio conference especially important.

A meeting of polio experts gathered in 1983 at the Pan American Health Organization (PAHO) in Washington, DC. ${ }^{16}$ It was the largest meeting of its kind in twenty years and included both Jonas Salk and Albert Sabin - the rival creators of the two polio vaccines. The much anticipated conference turned out to be a major anticlimax, however, for its eradicationist organisers, De Witt Stetten and Dorothy Horstmann, and for its rapporteur, Nobel laureate Frederick Robbins. Despite Stetten's plea to the assembled group at the beginning of the conference to consider the virtue of polio eradication, by the end of the meeting Robbins declared that the experts had reached no agreement on the issue except that polio would be more difficult to eradicate than smallpox. ${ }^{17}$

While it is true that eradication was a non-starter, eradication was debated with great vigour at one of the sessions, where the proponents had to admit they lost ground in bitter interchanges with WHO representatives, who championed primary health care and argued compellingly against an eradication programme. The fact that most polio experts did not favour polio eradication in no way stopped its proponents from their determination to move forward. Nor did the fact that polio was a disease with a low death rate in an era of massive child 
mortality from other infectious diseases slow them down. Most certainly they were not deterred by the fact that polio was a low (or zero) priority for most developing countries with endemic polio and for the families and communities of which they were composed. In fact, what polio did to children was never the issue for eradicationists, rather polio was simply a 'disease of opportunity', a stalking horse, picked to showcase the power of eradication to a largely sceptical, if not downright hostile, world.

Thus a small number of men, almost all from the North and mostly Americans, in the right place, at the right time, pushed for polio eradication regardless of what anyone else thought. One of them was William (Bill) Foege, who in his capacity as head of the vital Task Force for Child Survival, had the ear of James Grant, the charismatic head of UNICEF. For Foege and Grant, the WHO's anti-eradication position was simply an obstacle to be gotten around. ${ }^{18}$

An even more important proponent of eradication, though not as well known at the time, was Ciro de Quadros, the head of immunisation at the Pan American Health Organization (PAHO). PAHO, although technically a regional office of WHO, was older and saw itself as both superior to, and in competition with, its so-called 'parent' in Geneva. De Quadros' position at PAHO in the 1980s uniquely gave him a laboratory to prove the continued viability of eradication as a public health tool. ${ }^{19}$ The claim was made at the time that if a disease could be eradicated (more accurately 'eliminated') in the Americas - with their amazing range of rich and poor countries - then it could be eradicated anywhere in the world. De Quadros was psychologically committed to the idea of disease eradication in public health, as were many of those whose careers had started (and to some extent emotionally peaked) with the gruelling but often exhilarating smallpox eradication campaign, 1966-77.

Scientists and public health officials are usually not comfortable with the idea that emotions and psychological commitments have an impact in policy decisions. In the 'fact-based' community of science everything must conform to real world realities. But 'facts' often take a backseat to more human influences, because individuals matter, and individuals are not simply fact-making machines, but rather operate on a mixture of evidence and feelings. In the case of polio eradication, feelings often predominated. These were not the heart-rending emotions that many 
people feel when they see a crippled child; rather, it was the anguish felt by a small cadre of men who contemplated the permanent loss of a personally meaningful and cherished tool of public health: disease eradication.

In 1988 a few well-placed proponents found it relatively easily to manoeuvre the World Health Assembly (WHA) to declare for the global eradication of polio. ${ }^{20}$ However, it is important to realise that the ministers of health at the WHA had been incapable of giving informed consent to such a far-reaching programme, because they were not provided with the type of information necessary to understand what the declaration entailed. In part this was because the proponents were themselves ignorant of conditions on the ground in the various nations of Asia and Africa. Nor, in all probability, would they have provided totally accurate information, even if they had possessed it, because they were championing an idea, a cause, not a practical project. They believed that with enough 'political will' anything could be achieved. That was the lesson, realistic or not, that they believed the success of smallpox eradication had taught.

The road to polio eradication since 1988 has been a long and rocky one. While it was sold initially as a relatively quick and cheap campaign that would have 'infinite' economic benefits once universal polio vaccination was stopped, it has turned out to be neither quick, nor cheap, nor productive of infinite economic benefits. Instead of costing approximately US\$100 million (an early estimate) and ending by the year 2000 , it has already reached US $\$ 15.5$ billion (by 2013), and an additional estimated US\$5.5 billion will be needed in the years until full eradication is declared. ${ }^{21}$

A continuous stream of 'unexpected' obstacles - for example, eradication proponents belatedly discovering that India is not Brazil and Nigeria is not Peru, as well as the diverse biological traits of individuals and groups and the mutagenic qualities of the live-virus Sabin vaccine - have radically slowed the eradication of wild polio. ${ }^{22}$ Many of these 'unexpected' problems should not have come as surprises, since the polio medical literature and knowledgeable experts had warned the eradication champions of many of them from the beginning. The eradicationists' naive hope was that the campaign could be finished fast enough that the potential difficulties - especially problems from the Sabin oral vaccine itself - could be avoided. Speed was always of 
the essence, but speed was not always possible given the vast diversity of conditions in the developing countries. There was a lot of selfinflicted ignorance, and many important things that were unknown were things that supporters of the campaign didn't want to know.

For the leaders of the polio campaign it was vital that nothing be allowed to undermine the morale of their children's crusade. Dissenters were not welcome. As Bill Foege said: invite everyone to your conferences, but don't invite back those who disagree; eradication campaigns require enthusiasm - you don't want nay-sayers around. Such a position is probably a good way to maximise organisational esprit de corps but is not compatible with 'science', which is based on constant research and adjustments to changing data. This 'hear no evil, speak no evil' requirement often trumped existing knowledge, just as it powerfully deterred support for new polio research. Inconvenient information was not desired. ${ }^{23}$

Is eradication the highest form of immunisation work?

It is widely assumed that the eradication of wild polio virus throughout the world will constitute an unalloyed public good. Unfortunately, this is an untrue assumption. The notion that eradication is an indispensable weapon in the arsenal of public health was already being discredited even as the polio campaign was being launched in 1988 . The chronic problems of the campaign should subsequently have provided ammunition for that original critical position. In addition, the realisation that any eradicated disease for which public health immunisation ceased would automatically become a candidate biological weapon of mass destruction should have made further eradication efforts almost unthinkable. This became crystal clear after the discovery in the late 1980s that the Soviet Union had weaponised smallpox soon after it was eradicated and that smallpox was high on the list of potential terrorist weapons. On these grounds eradicationism as a tool of public health should have been as dead as a dodo. But it didn't die.

None of this happened because of the influence of those who support eradication as a tool of public health; their number has grown, and they have become more confident and aggressive. It appears that if and when polio eradication occurs, it will be used as definitive proof of the pivotal 
importance of eradicationism in global public health. If that occurs it will be nothing less than a disaster.

Anticipating the successful conclusion of the polio campaign, a proeradication conference organised by the Strüngmann Forum in Frankfurt, Germany, was held in 2010. This conference, attended by a host of prominent individuals and organisations, was in many ways radically different from the small numbers who had gathered at the Fogarty Centre in 1980 to fight for what then appeared to be a losing cause. Different, except in one regard: the emotional and philosophical commitment to eradication. At the Strüngmann conference the 'moral imperative' of eradication was not a question to be explored or debated but was rather a given, a foundational premise. No one asked: should diseases be eradicated? but rather, which ones and when?

The lessons attendees took from the ongoing polio campaign was not that unintended consequences are predictable, or that our ignorance is great, or that things often go wrong or that costs and tasks will escalate out of control, and so forth, nor that there are terrible collateral costs to developing countries when their own internally generated priorities are subordinated to outsiders. Instead, the lesson imbibed at the Strüngmann meeting was: We know what we did wrong with polio, so we will succeed in the future campaigns because we won't do things that way again.

The confidence of eradicationists seems to recognise no bounds. They seem to feel that they have learned past lessons so well, and that they are so smart and skilled, that they can start other eradication campaigns even before the polio effort has proven successful. Their argument is, we must make use of the polio infrastructure before it disappears. The polio infrastructure should be used not only to start an eradication campaign against measles, but to tackle multiple eradication campaigns, for example, mumps, rubella or what have you, piggybacking them one on top of the other. All are considered reasonable targets. In a meeting I attended at the Carter Center in Atlanta in April 2013, one CDC participant said they were looking at approximately eighteen infectious diseases with the expectation that as many as twelve of them were candidates for eradication or elimination campaigns many of these campaigns would be conducted simultaneously.

Where one would expect humility based on the polio eradication campaign's troubled record of cost overruns and delays one finds only 
hubris. However, hubris at the Strüngmann conference was disguised by a show of sophisticated studies and checklists of what to do and what not to do, which is no doubt far better than what preceded the adoption of the goal of polio eradication. Nonetheless, the eradicationists are still set on seizing the public health agendas for the entire developing world for decades to come.

When an article of faith - that eradication is a moral obligation from this generation to the next - takes hold and drives a global initiative, it blinds its proponents from seeing the world from the perspective of others. Since the eradicators already know what is good, all they have to do is 'educate' the leaders and peoples of the developing world to the 'facts' on which they will surely agree. If these leaders and peoples don't agree, then they need more education - or infusions of money, which can seduce even those who don't 'educate' well. If neither of those things work, or if countries change their minds later, then governmental elites must be by definition corrupt or stupid. The eradicationists are blinded by their faith and do not see the possibility of legitimate dissent. In many places developing countries have generated their own health and development priorities which are undermined by externally driven programmes, but this possibility is not the eradicationists' chief concern, to the extent that it is a concern at all.

Unfortunately, eradication campaigns entail a problem for developing countries that other types of externally generated disease control programmes do not: they are all or nothing affairs. To achieve the desired end, every country in the world must cooperate. There is no patience for any country not doing its part. There can be no tolerance of a country's government changing its mind. National authorities have no freedom to withdraw once their consent is given, even if the costbenefit analysis for their own populations changes radically. Eradication campaigns are inherently top-down operations in which targeted countries - usually former colonies of European empires - find themselves pressured to give up their hard-won autonomy for a 'greater good' that is determined and defined by someone other than themselves.

However, one thing is sure: no developing country has ever made the eradication of a global infectious disease its highest priority. Countries may want their endemic diseases under control, but disease eradication is not a natural concern. In addition, countries differ on which diseases they are most burdened by. In the case of polio, most countries 
ranked it a very low priority because other infections inflicted higher mortality on their children.

\section{The problem of global immunisation programmes}

External origination is not just an attribute of eradication programmes but of disease control as well. Even though control programmes are less binding, since withdrawal is always a possibility, the problems they cause developing countries are unfortunately very similar. For example, the choice of vaccines to be used is determined by a small group of experts primarily in the North. In fact, one man, Bill Gates, and his foundation, play an inordinate role in determining the immunisation priorities of the countries of the South. Top-down versus bottom-up priority setting is not a minor but a fundamental problem for the ex-colonial world. Most of the South is already caught in a tangle of northern economic investments, disinvestments, bi- and multi-lateral demands, controls, requirements, promises and threats that many have called neo-colonialism. The fact that global immunisation programmes are humanitarian in their aim rather than directly exploitive does not prevent their strongly destructive side effects.

The assumption made by global immunisation programmes is that the lives of children saved by a vaccine-preventable disease is a definitive good, and that those who have the power to select and supply vaccines are agents of that good. The fact that there are significant 'opportunity costs' for countries and their populations when they are pushed to accept a vaccine control programme, which may be of low priority to them, carries little weight against such a definitive act of humanitarianism. Indeed, to oppose such programmes must represent at best ignorance, and at worst an absolute evil.

One of the great virologists of the twentieth century, Alfred Prince, co-discoverer of the hepatitis B virus and creator of one of the first inexpensive hepatitis $\mathrm{B}$ vaccines, who was also a social activist fighting for mass hepatitis B immunisation, was an interesting dissenter from this common view found so often in the North. When I asked him why he worked on hepatitis B, he said that hepatitis B killed young and middle-aged adults who contributed to their national economies as well as to their own families, and that their deaths detracted (at some level) from whatever investments in education and resources their societies 
had been able to provide. This constituted, he felt, a major blow to their countries. However, if hepatitis B had killed children rather than adults, he never would have devoted his talents to developing a vaccine. There was no reason, he said, to save large numbers of children who would overwhelm their societies, strain their economies and natural resources, and result in a generation of under-employed and unemployed young people (especially males). Prince's goal was to help countries develop, not drown them in excess population or allow them to be ripped apart by angry, economically superfluous and armed young men. For him, saving children was not the ultimate goal - heresy though that might seem. The cost in economic development was too high. What passes for cost-benefit analysis in global immunisation programmes has traditionally not factored in the demographic consequences of immunisation of the sort that preoccupied Dr Prince or for that matter most ministries of finance in developing countries. ${ }^{24}$

Lurking under this fight between good and evil, ignorance and enlightenment, philanthropy and kleptocracy, and so on, is a lot of the old colonial mentality dressed up for modern times. ${ }^{25}$ Developing world governments are often seen as obstacles to saving the lives of children. Like bad parents, they must be circumvented by experts for the good of the child. If global policy makers fail to convince governments to act 'correctly' then global-level nanny organisations and 'selfless' philanthropists are required to intervene. It is hard to criticise those who wage the fight for the Greater Good. But families, communities, and nations all have to find their own way. That is what being adult and independent is all about. Mistakes will be made. Deaths will occur. Children will suffer. But corrections hopefully will ultimately occur.

After the publication of my book on polio I was asked: Do you want children to be paralysed by polio or killed by measles? My reply was no, of course not. But what is the price that should be paid to save those children? How big a cost to national autonomy, community self-determination, alternative disease prevention, or alternative economic and social developmental projects is reasonable - reasonable not to me but to the people in the developing world? The cost to national self-respect is high when health policy is determined by outsiders - whether global public health officials or philanthropists who seem to daily think up brilliant new health programmes to save the children of the developing world. 
Perhaps trying this thought experiment will make things clearer: If Britain or the United States were told that an Indian mega-billionaire wanted them to introduce a new vaccine that they had not prioritised, a vaccine that would push aside their own health or economic policies, how would they react? If an organisation like the WHO or THE Gates Foundation, but dominated by India, China and Kenya, set up goals for immunisation and held meetings manipulated by their nationals in which UK and US desires were subordinated to southern goals, what would the response be?

For a country like the United States with its own ghettos of poverty, sky-high minority incarceration, shocking levels of infant mortality, extreme wealth concentration and a Congress bought and sold by Wall Street banks, to tell the countries of the South how to set their priories, to condemn their unresponsive elites, corrupt rulers and unequal treatment of children, is grotesque hypocrisy. Freedom is the right to be wrong and to make mistakes. Independent countries have an inalienable right to determine their own destinies. They do not need Big Brothers intervening in the name of humanitarianism nor do they need self-appointed global elites claiming they own the routes to the greater good, as European imperialists used to intervene in the name of civilisation and Christianity. The cost to the South was too high then, and it is too high now.

\section{An alternative to the current policies of global humanitarian assistance}

What is the alternative to the present top-down system? It is simple, though unlikely to be carried out. If the northern countries and their philanthropists want to help southern countries and their children, then they must find out what the developing countries' priorities actually are. Bottom-up rather than top-down means paying attention to other people's goals rather than solipsistically pursuing one's own. Getting to know those local priorities needs slow and laborious work and requires dealing with the fact that developing countries are individually quite different.

One size doesn't fit all. For example, hepatitis B vaccine may be wanted in one country but not in another, where the vaccine might be objectively just as useful, but that country wants Japanese encephalitis 
immunisation instead. Global programmes constantly look for 'check lists' that try to homogenise the developing world so that the same vaccine can be introduced into all countries as part of one programme regardless of differences between them, and without any concern for what is actually desired. Global leaders must stop making vaccine and eradication policies and then trying to convince (read: force their views on) the leaders and people of the developing world. The North (and the new philanthropists as well) need to allow their money and expertise to be used by countries based on local priorities. They need to listen rather than talk. That is not the situation today, all claims notwithstanding.

\section{Notes}

1 W. Muraskin, The War Against Hepatitis B: A History of the International Task Force on Hepatitis B Immunization (Philadelphia: University of Pennsylvania Press, 1995).

2 W. Muraskin, The Politics of International Health: The Children's Vaccine Initiative and the Struggle to Develop Vaccines for the Third World (Albany: State University of New York Press, 1998).

3 W. Muraskin, Crusade to Immunize the World's Children: the Origin of the Bill and Melinda Gates Children's Vaccine Program and the Birth of the Global Alliance for Vaccines and Immunization (Los Angeles: University of Southern California, Marshall School, Global BioBusiness book, 2005).

4 Ibid.

5 W. Muraskin, The Rockefeller Foundation's Health Sciences Division: 19772002, An Overview of a Quarter Century of Fighting the Infectious Diseases of the Developing World (unpublished manuscript).

6 W. Muraskin, Polio Eradication and Its Discontents: An Historian's Journey Through an International Public Health (Un) Civil War (Hyderabad: Orient BlackSwan, 2012).

7 See 'Report of the Dahlem Workshop on the Eradication of Infectious Diseases, Berlin, March 16-22, 1997' in The Eradication of Infectious Diseases, edited by W. R. Dowdle and D. R. Hopkins (Chichester: John Wiley \& Sons, 1998), pp. 187-92. According to Foege, 'The lesson may be that WHO should be seen as a scientific organisation that becomes an eradication advocate only when outside forces are sufficiently strong to make the case. That may not be a bad model to follow in the future.' For him effective polio eradication required the formation of a 'great coalition' for which 'a service organisation, Rotary International' performed the 'catalytic 
role. The $\mathrm{WHO}$ was not the main actor. A similar situation existed for Guinea worm eradication (a project of the Carter Center) and for onchocerciasis (Merck). For Foege it was important to foster 'tailor made structures for each eradication effort' and not try to have one organisation (WHO) be the key to such efforts. Such views were not shared by the World Health Organization. (This note uses text from Muraskin, Polio and Its Discontents).

8 Two examples of this writer being enthralled with his subjects can be found in The War Against Hepatitis B and The Politics of International Health.

9 See for example many of the papers in Disease Eradication in the 21st Century: Implications for Global Health, edited by S. L. Cochi and W. R. Dowdle (Cambridge: MIT Press, 2011).

10 This has been said to me countless times but perhaps most strongly by Scott Halstead, formerly Acting Director of Health Science, Rockefeller Foundation, and the preeminent virologist of dengue hemorrhagic fever.

11 This is made clear in Muraskin, Crusade to Immunize the World's Children. It was while researching this book that the hidden cost of top-down 'Great Men' global health policy became impossible to ignore.

12 Muraskin, Polio Eradication and Its Discontents.

13 The Alma-Ata Declaration of 1978 emerged as a major milestone of the twentieth century in the field of public health, and it identified primary health care as the key to the attainment of the goal of 'Health for All'. See WHO, 'Declaration of Alma-Ata. International Conference on Primary Health Care, Alma- Ata, USSR, 6-12 September 1978', www.who.int/ publications/almaata_declaration_en.pdf.

14 See J. A. Walsh and K. S. Warren, 'Selective Primary Health Care: An Interim Strategy for Disease Control in Developing Countries', Social Science \& Medicine (Part C: Medical Economics), 14:2 (1980), pp. 145-63. There was nothing 'interim' about the intent of the strategy. The WHO emphasis on primary health care was seen as simply wrong-headed. It was seen as overly vague and without any targeted goals that could be measured. This strategy was a replacement for it. In addition, UNICEF, which increasingly saw itself as a rival of the WHO, was opposed to the Declaration of Alma Ata and offered itself as a white knight for its opponents. For a superb critique of UNICEF's championship of selective primary health care, see B. Wisner, 'GOBI versus PHC? Some Dangers of Selective PHC', Social Science and Medicine, 26:9 (1980), pp. 963-69.

15 'Report on the International Conference on the Eradication of Infectious Diseases. Can Infectious Diseases Be Eradicated?', Reviews of Infectious Diseases, 4:5 (September-October 1982), p. 915. 
16 'Proceedings of the International Symposium on Poliomyelitis Control held at the Pan American Health Organisation, Washington, DC, 14-17 March 1983', were edited by D. M. Horstmann, T. C. Quinn and F. C. Robbins, Review of Infectious Diseases, 6: Supplement 2 (May-June, 1984), pp. S301-600.

17 Ibid., p. S600.

18 See W. Muraskin, Polio Eradication and its Discontents, pp. 47-51 for a discussion of the roles of William Foege, James Grant and D. A. Henderson in championing polio eradication in the 'Declaration of Talloires', which was issued at a meeting called by Foege's Task Force for Child Survival in Talloires, France, 10-12 March 1988.

19 Muraskin, Polio Eradication and its Discontents, pp. 33-46.

20 David Salisbury, head of the WHO's Scientific Advisory Group of Experts, has said as much in an interview. He described a technical advisory group meeting on polio eradication that 'had been effectively outflanked after Talloires [since] polio eradication had already gone to the World Health Assembly and they had voted in favor of it before the technical advisory group had [even] considered it'. (Author interview, March 2010).

21 See The Henry J. Kaiser Family Foundation Global health Policy, 'The US Government and Global Polio Efforts', 28 May 2013, pp. 8-9, at http:// kff.org/global-health-policy/fact-sheet/the-u-s-government-and-globalpolio-efforts/ (accessed April 2014).

22 See 'Polio: The Problem of the Endgame Strategy' in Muraskin, Polio Eradication and Its Discontents, pp. 129-40.

23 Muraskin, Polio Eradication and Its Discontents, passim.

24 Ministries of finance have traditionally been seen as the enemy in global public health circles. The fact that they are powerful while ministries of health have been traditionally weak, has been a constant source of complaint. What has not been appreciated is that ministries of finance have to weigh many policy options: health-care interventions versus new roads, versus new schools, versus women's education, versus industry subsidies; and a host of other options. For public health practitioners, only health matters, which is a luxury many governments simply do not have.

25 I remember very well the comments made by a number of global policy makers when I first started my research: things were much easier when the world was colonised. Those men were good people who were strongly concerned about saving lives, but off the record they often sounded like unrepentant imperialists. 